Una semblanza de Omar Turconi

Sergio Antonucci

Question/Cuestión, Vol. 2, N 66, Agosto 2020

ISSN 1669-6581

https://perio.unlp.edu.ar/ojs/index.php/question/index

IICom-FPyCS-UNLP

\title{
UNA SEMBLANZA DE OMAR TURCONI
}

\section{A STORIE ABOUT OMAR TURCONI}

Sergio Antonucci Licenciado en Comunicación Social. Periodista. Docente e investigador. UNLP. Co autor del libro “Toda Una Vida” 85 Aniversario de Radio Universidad de La Plata. Editorial EDULP. Productor de radio.

Actualmente se desempeña en FM La Redonda de La Ciudad de La Plata. santonucci@perio.unlp.edu.ar

\section{Resumen}

Sergio Antonucci recupera la trayectoria de Omar Turconi. Profesor en la Facultad de Periodismo y Comunicación Social - UNLP. Director Ejecutivo de Radio Universidad de La Plata. Fue Director de Radio Nacional Bahía Blanca. Presidente de ARUNA (Asociación de Radiodifusoras Universitarias 
Nacionales). Consecuente militante por la Ley de Servicios de comunicación audiovisual. Por la comunicación entendida como un Derecho Humano.

\section{Palabras clave}

Radio, Universidad, Comunicación, Derecho, Gestión

\section{Abstract}

Sergio Antonucci recovers the trajectory of Omar Turconi. Professor at the Faculty of Journalism and Social Communication - UNLP. Executive Director of Radio Universidad de La Plata. He was Director of Radio Nacional Bahía Blanca- President of ARUNA (Association of National University Radio Broadcasters). Consistent militant by the Law of Audiovisual Communication Services. For communication understood as a Human Right.

\section{Keywords}

Radio, University, Communication, Law, Management

\section{Enlace}

https://go.ivoox.com/rf/55623364 